Original Article

\title{
ENANTIOMETRIC SEPARATION OF SITAGLIPTIN IN A FIXED DOSE COMBINATION FORMULA OF SITAGLIPTIN AND METFORMIN BY A CHIRAL LIQUID CHROMATOGRAPHIC METHOD
}

\author{
NAGADEEP JAISHETTY*, KAMARAJ PALANISAMY, ARTHANAREESWARI MARUTHAPILLAI
}

Department of Chemistry, SRM University, Kattankulathur, Channai-603203, Tamilnadu., India

Email: jnagadeep@yahoo.co.in

Received: 21 Sep 2017 Revised and Accepted: 23 Apr 2019

\begin{abstract}
Objective: Sitagliptin phosphate and metformin hydrochloride tablet is an FDA approved combination product for the treatment of diabetes mellitus type 2. There are no reported evidence for estimation of undesired (S)-sitagliptin in a combination product. The objective of this study was to develop a high sensitive liquid chromatography method for the determination of (S)-enantiomer of sitagliptin phosphate in a fixed dose combination formula of metformin and sitagliptin.
\end{abstract}

Methods: The proposed novel high-performance liquid chromatography (HPLC) method uses programmed gradient elution of a mixture of ethanoldiethylamine(DEA) 100:0.1 (v/v) as mobile phase-A and a mixture of methanol-water 60:40 (v/v) as mobile phase-B. The chromatographic conditions were designed to nullify the metformin interference and in which sitagliptin enantiomers elute first and followed by metformin. A satisfactory resolution ( $\geq 2.5$ ) between (S) -sitagliptin and active form (R)-sitagliptin was achieved with gradient elution on Chiralpak IA column $(5 \mu \mathrm{m}, 4 \times 250 \mathrm{~mm})$ at a flow rate of $0.5 \mathrm{ml} / \mathrm{min}$ and the detector wavelength set at $265 \mathrm{~nm}$. The injection volume set as $10 \mu \mathrm{l}$. The developed method has been validated as per the International Conference on Harmonisation (ICH) guidelines.

Results: The proposed HPLC method for determination of (S)-sitagliptin, showed good linearity in the concentration range of $0.5 \mu \mathrm{g} / \mathrm{ml}$ to 13.6 $\mu \mathrm{g} / \mathrm{ml}$ and capable to quantify accurately up to the lowest level (LOQ) of $0.017 \%$. The validated method was successfully applied to quantify the (S)sitagliptin for different marketed formulations of sitagliptin with metformin and sitagliptin alone, and the corresponding recovery values were found to be in the range of $95.1 \%$ to $98.4 \%$.

Conclusion: The proposed validated HPLC method was found to be suitable for the quantitative determination of (S)-sitagliptin in the formulations of sitagliptin with metformin and sitagliptin alone.

Keywords: Sitagliptin phosphate, Metformin hydrochloride, Enantiomeric separation, Method development, Method validation

(C) 2019 The Authors. Published by Innovare Academic Sciences Pvt Ltd. This is an open-access article under the CC BY license (http://creativecommons.org/licenses/by/4.0/] DOI: http://dx.doi.org/10.22159/ijpps.2019v11i6.22699

\section{INTRODUCTION}

Sitagliptin phosphate (SIT) is chemically 7-[(3R)-3-amino-1-oxo-4(2,4,5 trifluorophenyl) butyl]-5,6,7,8-tetrahydo-3-(trifluoromethyl)1,2,4-Triazolo [4,3-a] pyrazine phosphate (1:1) monohydrate (fig. 1). SIT is used for the improvement of glycemic control among patients with type II diabetes mellitus, either as monotherapy or as combination therapy with metformin hydrochloride (MET) when the single agent does not provide adequate glycemic control [1-2]. The combination of sitagliptin phosphate and metformin hydrochloride proved to be effective in controlling the metabolic syndrome and resulted in significant weight loss, the reversal of insulin resistance is let and adipocyte hypertrophy and alleviated hepatic steatosis [3]. Merck markets SIT in combination with MET in a single dosage form, brand name as Janumet. In Janumet these drugs are available in 50/500 $\mathrm{mg}$ and 50/1000 $\mathrm{mg}$ of SIT and MET, respectively.

During the synthesis of sitagliptin, there is a possibility of carrying an undesired (S)-enantiomer of enantiopure sitagliptin, therefore the enantioselective analytical method is necessary to ensure its therapeutic efficacy and safety. The development of analytical methods for the assessment of enantiomeric purity is challenging due to the fact that enantiomers possess virtually identical properties [4]. However, no methods have been reported for quantification of undesired (S)-enantiomer of sitagliptin in a combination formula of SIT and MET. For drug products, it should be confirmed that the eutomer is present in the required dose while the distomer level should be analyzed as an impurity, as prescribed in the guidelines imposed by the International Conference on Harmonization ( $\mathrm{ICH}$ ), more precisely in guideline Q6A (decision tree number 5) [5]. But literature survey reveals that there are analytical methods available for determination of (S)-enantiomer of sitagliptin in bulk drug and formulation samples of sitagliptin phosphate using chiral stationary phases by HPLC [6-7]. The reported chiral chromatographic methods were not suitable for estimation of (S)enantiomer of sitagliptin in combination drug product of sitagliptin and metformin. Few methods have been reported only for estimation of SIT and metal one and in combination [8, 9-20, 21]. The combination product Janumet contains a high content of metformin i.e. $1000 \mathrm{mg}$ for $50 \mathrm{mg}$ of sitagliptin. Therefore, it is challenge to develop a sensitive and high-throughput assay for quantification of sitagliptin enantiomers in the presence of metformin. Optimization of sample preparation and chromatographic conditions are needed to avoid metformin interference in chromatography. The aim of the present article describes the quantitative determination of (S)-enantiomer of sitagliptin phosphate in a combination dosage of SIT and MET by using reverse phase chromatography. In continuation of our research work for determination of impurities in pharmaceutical dosage forms [22-23], the present communication forms the first report of a simple, sensitive and reproducible method for determination of (S)-enantiomer of sitagliptin phosphate in combination product of SIT and MET.

\section{MATERIALS AND METHODS}

\section{Chemicals}

Sitagliptin and its (S)-enantiomer (fig. 1) were provided by Auro pharma, Hyderabad, India. Metformin was provided by Granules, India. Commercially available Janumet (immediate release) and Janumet XR (extended release) tablets nominally containing 64.25 mg of sitagliptin phosphate monohydrate and $1000 \mathrm{mg}$ of metformin were purchased at a local drugstore. HPLC grade methanol, ethanol, and diethylamine were purchased from Merck, Germany. 
<smiles>N[C@@H](CC(=O)N1CCn2c(nnc2C(F)(F)F)C1)Cc1cc(F)c(F)cc1F</smiles>

(A)<smiles>N[C@@H](CC(=O)N1CCn2c(nnc2C(F)(F)F)C1)Cc1cc(F)c(F)cc1F</smiles>

(B)

Fig. 1: Chemical structures of (A) sitagliptin and (B) (S)-enantiomer of sitagliptin

\section{Equipment}

The system used for method development and validation study was Agilent HPLC 1200 series (Agilent technologies, Germany) with Ezchrom elite software equipped with G1322A degasser, G1311A quaternary pump, G1315C auto-injector, G16A column oven and G1315C DAD detector.

\section{Chromatographic conditions}

The chromatographic conditions were optimized using a polysaccharide derivative immobilized on silica particles as chiral stationary phase Chiralpak IA (250 x $4.6 \mathrm{~mm}, 5 \mu \mathrm{m}$, Daicel make) which was safeguarded with a $1 \mathrm{~cm}$ long guard column. The mobile phase-A contains ethanol with $0.1 \%$ of diethylamine and mobile phase-B contains a mixture of methanol-water $60: 40(\mathrm{v} / \mathrm{v})$. The flow rate was $0.5 \mathrm{ml} / \mathrm{min}$. The developed gradient program was: 0.01 $\min -0 \%$ B, 18.0 min- $0 \%$ B, 22.0 min- $100 \%$ B, 48.0 min- $100 \%$ B, $52.0 \mathrm{~min}-0 \% \mathrm{~B}$ and $78.0 \mathrm{~min}-0 \% \mathrm{~B}$. The detection was carried out at a wavelength of $265 \mathrm{~nm}$. The injection volume was $10 \mu \mathrm{l}$. The column and sample compartment temperature was maintained at 25 ${ }^{\circ} \mathrm{C}$. The developed conditions in an isocratic mode using mobile phase-A with a run time 20 min can also be used for sitagliptin bulk drug and formulations for monitoring of (S)-sitagliptin. All calculations concerning the quantitative analysis were performed with external standardization by measurement of peak areas.

\section{System suitability solution}

A stock solution of (S)-enantiomer $(0.015 \mathrm{mg} / \mathrm{ml})$ and sitagliptin phosphate $(0.015 \mathrm{mg} / \mathrm{ml})$ were prepared by dissolving the appropriate amount of the substances in ethanol and diluted the solution to get concentration $4.5 \mu \mathrm{g} / \mathrm{ml}$ was used as system suitability solution.

\section{Sample preparation}

The samples were prepared by weighing about $300 \mathrm{mg}$ of sitagliptin phosphate equivalent Janumet tablet powder into $100-\mathrm{ml}$ flask and dissolving in ethanol by sonication to get $3.0 \mathrm{mg} / \mathrm{ml}$ concentration of sitagliptin phosphate. Addition of $2 \mathrm{ml}$ of water to each preparation was done, before proceeding for sonication. Sample solutions were filtered through $0.45 \mu \mathrm{m}$ syringe filter before injecting into HPLC.

\section{Method validation}

The developed liquid chromatographic method for quantification of (S)-enantiomer of sitagliptin in formulated samples was validated according to ICH Guidelines [25-26]. As a part of the validation study, the method was evaluated for parameters mentioned in guidelines like system suitability, specificity, precision, linearity, the limit of detection, the limit of quantification, recovery studies, solution stability and robustness of chromatographic conditions.

\section{RESULTS AND DISCUSSION}

\section{Method development}

Method development was initiated using marketed formulation Janumet tablets $50 / 1000 \mathrm{mg}$ strength. Optimization of chromatographic conditions and sample preparation experiments were carried a parallel but we noticed, it is impractical to optimize chromatographic conditions for low-level quantification of (S)enantiomer in the presence of completely dissolved metformin, hence sample preparation optimization trails were taken initially followed by optimization of chromatographic conditions.

\section{Sample preparation optimization}

Sample preparation is an important step in the pharmaceutical analysis to control matrix effects and to improve the sensitivity as well as to achieve better analyte recovery. A minimum of 3.0 $\mathrm{mg} / \mathrm{ml}$ of sitagliptin phosphate solution required to get optimum sensitivity for (S)-enantiomer $\$ 0.05 \%$ ] [24] relative to its eutomer. If the metformin completely dissolved in a chosen diluent, the sample with $3.0 \mathrm{mg} / \mathrm{ml}$ of sitagliptin of Janumet $50 / 1000 \mathrm{mg}$ solution contains about $46.6 \mathrm{mg} / \mathrm{ml}$ of metformin. The matrix metformin effect is a major concern and needs to be minimized by choosing a solvent in which the metformin solubility is less and sitagliptin phosphate is fully soluble. Different solvent systems from non-polar to polar were practically inquired in which metformin partially soluble or insoluble and whereas sitagliptin phosphate having more solubility. Dramatically in most of the solvents both metformin and sitagliptin phosphate were exhibited similar kind of solubility. But only in ethanol and dimethyl sulphoxide, the solubility of metformin is $<6 \mathrm{mg} / \mathrm{ml}$ and sitagliptin phosphate is fully soluble. Out of these two solvents, ethanol as a diluent was chosen to get good compatibility with chiral stationary phases. The (S)-enantiomer of sitagliptin phosphate recovery was good when the tablet powder was in contact with at least $2 \mathrm{ml}$ of water before addition of ethanol during sample preparation. Sonication of about $30 \mathrm{~min}$ is necessary for effective extraction of (S)-enantiomer from tablet powder.

\section{Chromatographic conditions optimization}

Optimization trails for chromatographic conditions can be minimized by effective sample preparation i.e. by minimizing the matrix effects. Metformin matrix effect was minimized by choosing ethanol as diluent. The reported literature methods of reverse phase and normal phase were evaluated by injecting metformin solution and in which metformin is eluting as flat peak and have no separation with sitagliptin. To develop a rugged and suitable liquid chromatography method for the separation of sitagliptin enantiomers in the presence of MET, different mobile phases and stationary phases were employed. To achieve the chromatographic separation, various chiral columns like Chiralcel ODH, Chiralpak ASH, Lux Amylose 2, Daicel Chiralpak AD 3 and Whelk-O-1 (Merck) were used. Various experiments were conducted, to select the best stationary and mobile phases that would give optimum resolution and selectivity of the enantiomers and separation with metformin. Poor separation of enantiomers with metformin was found on Chiralcel OD-H, Whelk-O-1 and Chiralpak AS-H columns using different possible mobile phases with normal phase conditions. Metformin $\log ^{\mathrm{P}}$ value is very low indicating its polar nature and is sparingly soluble in non-polar solvents, hence elution with normal phase chromatography was not suitable and reverse phase chromatography is the only option to wash out a high concentration of metformin in the sample solution.

Various trials with ethanol, different ratios of ethanol-water and different ratios of methanol-water as mobile phases were used in our initial efforts in the reverse phase separation. The trials were made initially in isocratic mode using Chiral IA, IB and IC columns. In isocratic mode, sitagliptin isomers separation is less than 2.0 and the elution of metformin is occurring even after $100 \mathrm{~min}$ of runtime, may be due to insufficient elution strength of mobile phase. Hence gradient elution was designed in such a way that, to elute sitagliptin 
enantiomers within $20 \mathrm{~min}$ and followed by elution of metformin. There is an indication of separation of metformin with sitagliptin enantiomers in gradient mode on Chiralpak IA column using a $0.1 \%$ diethylamine in ethanol as mobile phase-A and methanol-water $60: 40(\mathrm{v} / \mathrm{v})$ as mobile phase- $\mathrm{B}$ at $0.7 \mathrm{ml} / \mathrm{min}$ flow rate. The decrease in flow from $0.7 \mathrm{ml} / \mathrm{min}$ to $0.5 \mathrm{ml} / \mathrm{min}$ further increased the resolution between sitagliptin enantiomers. The optimized final conditions with Chiralpak IA were given in section-Chromatographic conditions. The chromatogram was monitored at wavelength 265 $\mathrm{nm}$. The resolution between enantiomers was found to be greater than 2.0 and no interference observed from metformin. In the optimized method, the typical retention time of (S)-enantiomer, sitagliptin and metformin were about 13.6, 15.7 and $51.1 \mathrm{~min}$ respectively. The chromatogram of a mixture of sitagliptin enantiomers alone and (S)-enantiomer of sitagliptin spiked with tablet sample are displayed in fig. 2C and $3 \mathrm{~A}$.

\section{Analysis of formulated samples}

Analyzed the formulated samples of fixed dose combination of sitagliptin and metformin tablets (Janumet, Janumet XR) 50/1000 mg strength for determination of undesired (S)-enantiomer of sitagliptin. Each sample preparation was preceded by taking tablet powder equivalent to $150 \mathrm{mg}$ of sitagliptin to the 50 -ml flask to make the concentration of sitagliptin 3 $\mathrm{mg} / \mathrm{ml}$. Added $2 \mathrm{ml}$ of water before the addition of ethanol and sonicated for $30 \mathrm{~min}$ with intermittent shaking. Filtered samples were injected into HPLC with chromatographic conditions mentioned in sectionChromatographic conditions. Before running the samples into HPLC, system suitability was tested by injecting racemic sitagliptin solution in isocratic mode with a run time $20 \mathrm{~min}$. The same kind of sample preparation applied for the entire method validation study and placebo preparations. The typical chromatograms of system suitability solution and formulation sample are given in fig. $2 \mathrm{C}$ and $3 \mathrm{~B}$.
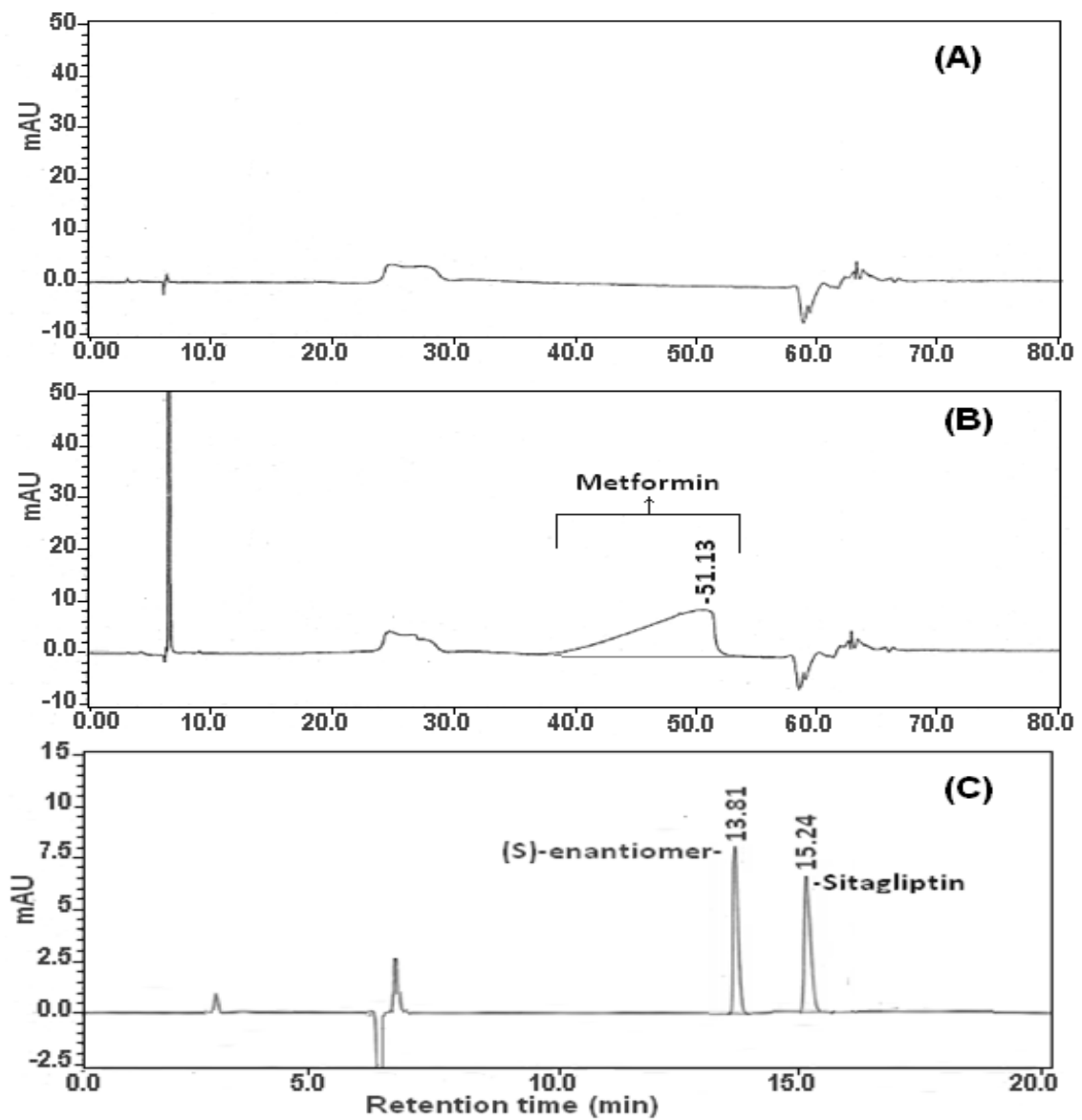

Fig. 2: Typical chromatograms of (A) Blank as a diluent injection (B) Placebo solution containing metformin (C) System suitability solution containing racemic sitagliptin

\section{Method validation}

\section{System suitability}

System Suitability tests are an integral part of chromatographic methods. They are used to verify the adequacy of the resolution and reproducibility of the chromatographic system for the analysis to be done. The parameters of these tests are column efficiency (number of theoretical plates), tailing of the chromatographic peak, peak resolution factor, and repeatability as \% RSD of peak area for six injections. The typical chromatogram is given in fig. $2 \mathrm{C}$. The results of system suitability tests for the proposed method are listed in table 1.

\section{Specificity}

Specificity is the ability of the method to assess unequivocally the analyte in the presence of matrix components. The specificity of the developed method was determined by the analysis of a solution containing (S)-enantiomer and its main related substances of sitagliptin and metformin. There were no interferences observed at retention time S-enantiomer of sitagliptin from diluent and with metformin matrix. The typical chromatograms are given in fig. $2 \mathrm{~A}$ and $2 \mathrm{~B}$.

\section{Precision}

The repeatability of the method was examined by six-fold analysis of by spiking $4.5 \mu \mathrm{g} / \mathrm{ml}$ of (S)-enantiomer on formulation sample to obtain $3000 \mu \mathrm{g} / \mathrm{ml}$ solution of sitagliptin. The \% RSD of retention times and peak areas for each enantiomer were well within $2.0 \%$. The intermediate precision was also evaluated over $2 \mathrm{~d}$ by performing six successive preparations each day. The results are presented in table 2 . 

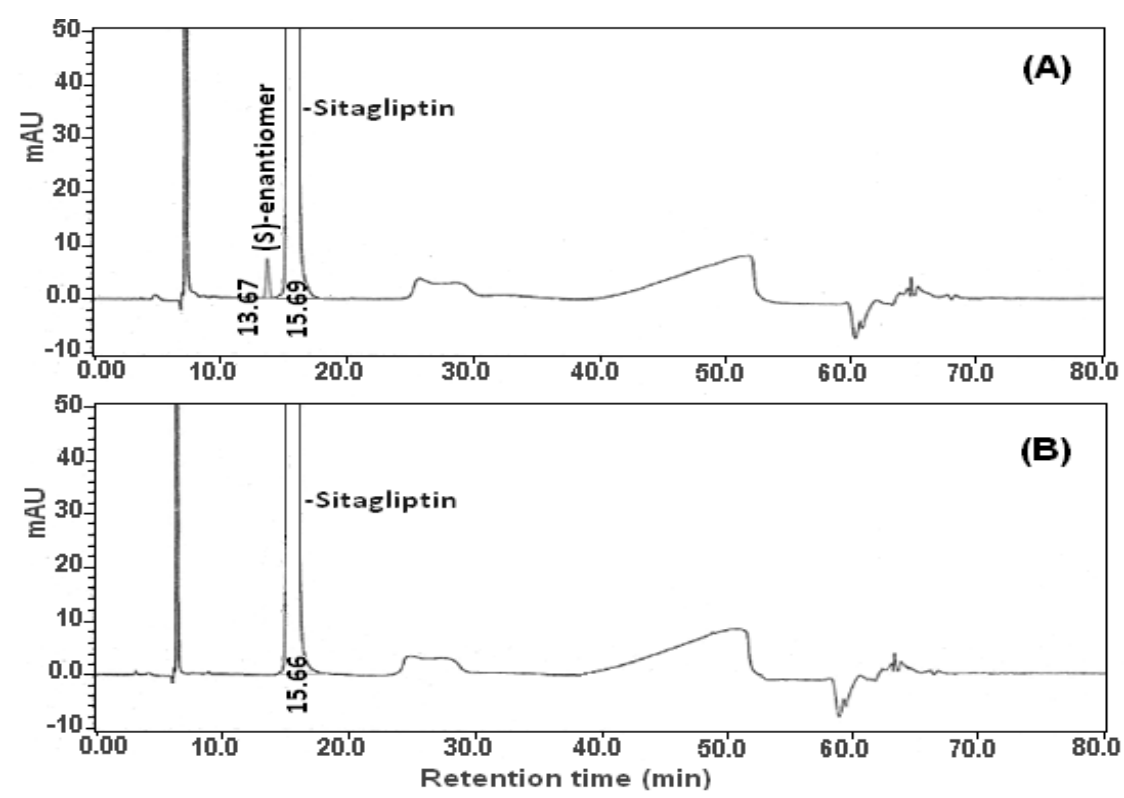

Fig. 3: Typical chromatograms of (A) Sample solution of combination tablets (Janumet) spiked with (S)-enantiomer at $0.3 \%$ level (B) Sample solution of combination tablets (Janumet)

Table 1: System suitability parameters

\begin{tabular}{llllll}
\hline Compound & Rt & Rs & N & T & Area \\
\hline Sitagliptin & $15.26 \pm 0.01$ & $3.8 \pm 0.05$ & $9586 \pm 75$ & $1.11 \pm 0.01$ & $21718 \pm 240$ \\
(S)-enantiomer & $13.80 \pm 0.03$ & -- & $8672 \pm 110$ & $1.18 \pm 0.01$ & $22510 \pm 182$ \\
\hline
\end{tabular}

${ }^{*} \mathrm{n}=$ Number of experiments, each value expressed as mean \pm standard deviation $(\mathrm{n}=6)$, Rt: retention time, Rs: USP resolution, N: number of theoretical plates (USP tangent method), T: USP tailing, RSD: relative standard deviation

\section{Linearity of (S)-enantiomer of sitagliptin phosphate}

The linearity of detector response was assessed by preparing the calibration curve of sample solutions (S-enantiomer of sitagliptin) of 7 concentration levels covering from $0.5 \mu \mathrm{g} / \mathrm{ml}$ to $13.6 \mu \mathrm{g} / \mathrm{ml}$ in ethanol diluent. A regression curve was obtained by plotting peak area versus respective concentration, using the least squares method. The slope and intercept of the calibration curve are exhibited in table 2.

Limit of detection and limit of quantification of (S)-enantiomer of sitagliptin phosphate

The limit of detection (LOD) is defined as the lowest concentration of analyte that can be clearly detected above the baseline signal, while the limit of quantification (LOQ) is defined as the lowest concentration of analyte that can be quantified with suitable precision and accuracy. The linearity performed above is used for the determination of the limit of quantification and detection. Residual standard deviation method was applied to predict the LOQ and LOD values using the following formula and the precision was established at these predicted levels. The results are presented in table 2 .

$$
L O D=3.3 \times \frac{S D}{S} L O Q=10 \times \frac{S D}{S}
$$

Where SD = residual standard deviation of response; $\mathrm{S}=$ slope of the calibration curve.

Table 2: Validation results of the developed chiral LC method

\begin{tabular}{|c|c|}
\hline Validation parameter & Results \\
\hline \multicolumn{2}{|l|}{ Repeatability (n=6, \%RSD) } \\
\hline Retention time (S-enantiomer) & 0.2 \\
\hline Peak area (S-enantiomer) & 1.2 \\
\hline \multicolumn{2}{|c|}{ Intermediate precision ( $=12, \%$ RSD) } \\
\hline Retention time (S-enantiomer) & 0.3 \\
\hline Peak area (S-enantiomer) & 1.8 \\
\hline \multicolumn{2}{|l|}{ LOD-LOQ (S-enantiomer) } \\
\hline Limit of detection $(\mu \mathrm{g} / \mathrm{ml})$ & 0.1551 \\
\hline Limit of quantification $(\mu \mathrm{g} / \mathrm{ml})$ & 0.5172 \\
\hline Precision at LOQ ( $n=6, \%$ RSD) & 3.4 \\
\hline \multicolumn{2}{|l|}{ Linearity (S-enantiomer) } \\
\hline Calibration range $(\mu \mathrm{g} / \mathrm{ml})$ & 0.5185 to 13.645 \\
\hline Calibration points & 7 \\
\hline Correlation coefficient & 0.9999 \\
\hline Slope & 5020.8 \\
\hline Intercept & -655.5 \\
\hline
\end{tabular}

\footnotetext{
${ }^{*} \mathrm{n}=$ Number of experiments, RSD=Relative standard deviation
} 
Recovery study of (S)-enantiomer of sitagliptin phosphate in the formulation sample

Recovery experiments were conducted to determine the accuracy of the developed method for the quantification of (S)-sitagliptin in a combination product. The study was carried out in triplicate by spiking different levels of (S)-sitagliptin i.e. $0.017 \%$ (LOQ), $0.075 \%$, $0.15 \%, 0.23 \%$ and $0.3 \%$ of the target analyte concentration $(3.0$ $\mathrm{mg} / \mathrm{ml}$ of sitagliptin). The study results are given in table 3 .

Table 3: Recovery results of (S)-enantiomer in combination tablets

\begin{tabular}{llll}
\hline Accuracy level & aAmount added $(\boldsymbol{\mu g})$ & Amount recovered $(\boldsymbol{\mu g})$ & Recovery $(\%)$ \\
\hline LOQ & 51.64 & $49.11 \pm 1.59$ & $95.1 \pm 3.1$ \\
$50 \%$ & 229.49 & $223.98 \pm 3.95$ & $97.6 \pm 1.7$ \\
$100 \%$ & 458.98 & $447.05 \pm 5.55$ & $97.4 \pm 1.2$ \\
$150 \%$ & 688.47 & $677.46 \pm 9.03$ & 1.8 \\
$300 \%$ & 1376.95 & $1352.16 \pm 15.78$ & 1.2 \\
\hline
\end{tabular}

$*_{\mathrm{n}}=$ Number of experiments, each value expressed as mean \pm standard deviation $(\mathrm{n}=3)$, a Amount added to 100 ml of test preparation, RSD: relative standard deviation

\section{Robustness}

Robustness of the method was performed by deliberately changing the chromatographic conditions. The flow rate of the mobile phase was changed from 0.5 to $0.4 \mathrm{ml} / \mathrm{min}$ and $0.6 \mathrm{ml} / \mathrm{min}$. The methanol strength of mobile phase- 2 was varied by $\pm 5 \%$ while column temperature was varied by $\pm 5{ }^{\circ} \mathrm{C}$. The solution of (S)-sitagliptin was spiked with the formulation sample was injected in each varied condition and the resolution between the isomers was checked. In all deliberately varied conditions, the resolution between the isomers was found to be well within the acceptance limit of $2 \%$ indicating the method robustness.

\section{Solution stability and mobile phase stability}

The variability in the estimation of (S)-sitagliptin in formulation sample was studied by keeping the solution at room temperature on bench top for $2 \mathrm{~d}$. The content of (S)-enantiomer was checked for 12 $\mathrm{h}$ interval up to the study period using the same mobile phase. The results are falling within $\pm 10 \%$ during the study. It is confirmed that standard solutions, sample solutions, and the mobile phase were stable up to $48 \mathrm{~h}$ for estimation of (S)-enantiomer.

\section{CONCLUSION}

A new chiral Reverse Phase-High Performance Liquid Chromatography (RP-HPLC) method was successfully developed for sitagliptin phosphate enantiomers in a fixed dose combination of sitagliptin phosphate and metformin hydrochloride tablets. This method is simple, accurate and has provided good linearity, precision, and reproducibility for determination of undesired (S)enantiomer of sitagliptin. The applicability of this method was tested by formulations of immediate release and extended release tablets of sitagliptin phosphate and metformin. The method can be used in quality control for monitoring of undesired (S)-enantiomer during manufacturing and for the quantitative determination of undesired (S)-enantiomer of sitagliptin in marketed formulations of sitagliptin phosphate with metformin and sitagliptin phosphate alone.

\section{ACKNOWLEDGMENT}

The authors wish to thank SRM University for encouragement and permission to communicate the manuscript for publication.

\section{AUTHORS CONTRIBUTIONS}

N. J. and K. P. designed experiments; N. J. performed experiments and analyzed the data; A. M. wrote the manuscript; N. J. and K. P. revised and edited the manuscript.

\section{CONFLICT OF INTERESTS}

The authors declare no conflict of interest

\section{REFERENCES}

1. P K, R JR, Js K. A comparative study of efficacy and safety among metformin with sitagliptin, metformin with voglibose, and metformin with glimepiride in patients with type 2 diabetes mellitus. Asian J Pharm Clin Res 2017;10:313-6.
2. Singh RJ, Gupta AK, Kohli K. Diabetes mellitus: a review with edge of SGLT2 inhibitors. Int J Curr Pharm Sci 2018;10:1-2.

3. Souza Mello V, Gregorio BM, Cardoso-de-Lemos FS, de Carvalho L, Aguila MB, Mandarim-de-Lacerda CA. Comparative effects of telmisartan, sitagliptin and metformin alone or in combination on obesity, insulin resistance, and liver and pancreas remodeling in C57BL/6 mice fed on a very high-fat diet. Clin Sci 2010;119:239-50.

4. Beesley TE, Scott RP. Chiral chromatography. John Wiley and Sons; 1998.

5. Guideline IH. Specifications: test procedures and acceptance criteria for new drug substances and new drug products: chemical substances. Q6A. International Conference on Harmonisation of Technical Requirements for Registration of Pharmaceuticals for Human Use, Geneva, Switzerland; 1999.

6. Reddy BV, Raman N, Kumar BS, Rambabu C. Chiral separation of sitagliptin phosphate enantiomer by HPLC using amylose based chiral stationary phase. J Pharm Res 2013;7:546-50.

7. Ramesh T, Rao PN, Suresh K. Enantiomeric separation of sitagliptin by a validated chiral liquid chromatographic method. Anal Methods 2014;6:223-8.

8. Deepthi V, Poornima Y, Devala RG, Reddy ST. Stability indicating RP-HPLC method for analysis of sitagliptin in the bulk drug and its pharmaceutical dosage form. Int J Pharm Pharm Sci 2013;5:320-5.

9. Jeyabalan G, Nyola N. Analytical method development and validation of sitagliptin phosphate monohydrate in pure and tablet dosage form by derivative spectroscopy. J Appl Pharm Sci 2013;3:95.

10. Maste MM, Parate AN, Bhat AR. Validation and application of a high-performance liquid chromatography method for estimation of sitagliptin phosphate from bulk drug and pharmaceutical formulation. Asian J Res Chem 2011;4:1466-8.

11. Khan G, Sahu D, Agrawal YP, Sabarwal N, Jain A, Gupta AK. Simultaneous estimation of metformin and sitagliptin in tablet dosage form. Asian J Biochem Pharm Res 2011;1:352-8.

12. Raja T, Rao AL. Validated RP-HPLC method for simultaneous estimation of metformin hydrochloride and sitagliptin phosphate in bulk drug and pharmaceutical formulation. Int J Pharm Chem Biol Sci 2012:2:696-702.

13. Vasudevan M, Ravi J, Ravisankar S, Suresh B. ION-pair liquid chromatography technique for the estimation of metformin in its multicomponent dosage forms. J Pharm Biomed Anal 2001;25:77-84.

14. Malleswararao CS, Suryanarayana MV, Mukkanti K. Simultaneous determination of sitagliptin phosphate monohydrate and metformin hydrochloride in tablets by a validated UPLC method. Sci Pharm 2011;80:139-52.

15. El-Bagary RI, Elkady EF, Ayoub BM. Liquid chromatographic determination of sitagliptin either alone or in ternary mixture with metformin and sitagliptin degradation product. Talanta 2011;85:673-80.

16. Loni AB, Ghante MR, Sawant SD. Method development and validation for simultaneous determination of sitagliptin phosphate and metformin hydrochloride by RP-HPLC in bulk and tablet dosage form. Asian J Pharm Sci Res 2012;2:23-36. 
17. Shyamala M, Mohideen S, Satyanarayana T, Narasimha Raju CH, Suresh Kumar P, Swetha K. Validated RP-HPLC for simultaneous estimation of sitagliptin phosphate and metformin hydrochloride in the tablet dosage form. Am J Pharm Tech Res 2011;1:193-201.

18. Peraman R, Gowra CS, Reddy YP, Peruru KK. Stabilityindicating RP-HPLC method for simultaneous determination of metformin hydrochloride and sitagliptin phosphate in dosage forms. Chromatographia 2013;76:1153-62.

19. Nc K, Jk P. Method development and validation of a reversedphase liquid chromatographic method for the simultaneous estimation of selected antidiabetic drugs in the presence of their degradation products. Asian J Pharm Clin Res 2018;11:345-52.

20. Trivedi A, Dixit N, Jhade DN. Modified quantification through high-performance liquid chromatography analysis for canagliflozin and metformin hydrochloride in bulk and tablets using eco-friendly green solvents. Int J Appl Pharm 2017;9:97101.
21. Kulkarni AA, Vaidya IS. Flow injection analysis: an overview. J Crit Rev 2015;2:19-4.

22. Nagadeep J, Kamaraj P, Arthanareeswari M. Gradient RP-HPLC method for the determination of potential impurities in dabigatran etexilate in bulk drug and capsule formulations. Arabian J Chem 2015. https://doi.org/10.1016/j.arabjc.2015.09.006

23. Jaishetty N, Palanisamy K, Maruthapillai A, Jaishetty R. Trace level quantification of the (-) 2 -(2-amino-5-chlorophenyl)-4cyclopropyl-1, 1, 1-trifluoro-3-butyn-2-ol genotoxic impurity in efavirenz drug substance and drug product using LC-MS/MS. Sci Pharm 2015;84:456-66.

24. Guideline IH. Impurities in new drug products Q3B (R2), Current Step; 2006. p. 4.

25. International Conference on Harmonization of Technical Requirements for Registration of Pharmaceuticals for Human use. Validation of Analytical Procedures; Text and Methodology ICH Q2 (R1); 2005.

26. Guideline IH. Good manufacturing practice guide for active pharmaceutical ingredients. Q7A, Current step; 2000. p. 4. 